\title{
Besin Okuryazarlığı, Yeme Farkındalığı ve Beslenme
}

\author{
Food Literacy, Mindful Eating and Nutrition
}

Hakan BOR ${ }^{1}$, Mendane SAKA ${ }^{2}$

\begin{abstract}
ÖZ
Günümüzde gelişen teknolojiyle beraber besinler raflarda sağlık için zararlı ve yararlı özellikleri içlerinde barındırarak çok farklı şekillerde yer almaya başlamıştır. Bunun sonucunda bireylerin bu aşırı besin çeşitliliği içinde doğru ve ihtiyaç duyduğu besini seçmesi karmaşık ve zor bir hal almıştır. Ayrıca hızlı yaşam tarzının etkin olmasıyla beraber yemek yeme alışkanlıkları da geçmişten farklı olarak değişim göstermeye başlamıştır. Buna bağlı olarak da hızlı yaşam tarzı nedeniyle değişen beslenme alışkanlıkları (hazır yemek yeme, hızlı yemek yeme, farkındalıksız yemek yeme vs.) yaşamın devamı için en temel gereksinimlerden biri olan sağlıklı beslenme alışkanlıklarının bozulmasına ve sağlıksız beslenmenin yaygınlaşmasına yol açmaktadır. Sonuç olarak bu iki durum sağlıksız beslenmeden kaynaklı kronik hastalıkları ve sağlık harcamalarını artırmaktadır. Bu derleme makalede artan besin çeşitliliği ve hızlı yaşam temposu içinde ideal sağlık durumunu yeterli ve dengeli bir beslenme şekliyle sağlamak adına besin okuryazarlığı, yeme farkındalığı kavramlarının tanımlarının, önemlerinin ve bu kavramların beslenmeyle olan ilişkilerinin ortaya konulması amaçlanmıştır.
\end{abstract}

Anahtar Kelimeler: Besin okuryazarlığı, Beslenme, Sağlık, Yeme farkındalığı.

\begin{abstract}
Nowadays, with the developing technology, foods have started to take place on the shelves in many different ways by containing harmful and beneficial properties for health. As a result, it has become complicated and difficult for individuals to choose the right and needed food in this extreme food variety. In addition, with the effective fast lifestyle, eating habits have started to change differently than in the past. Therefore, changing nutritional habits (eating fast foods, eating fast, eating without mindfulness, etc.) due to the fast lifestyle lead to a decrease in healthy eating habits which is one of the most basic requirements for the continuation of life and the spread of unhealthy nutrition. As a result, these two situations increase chronic diseases and health expenditures caused by unhealthy nutrition. In this review article, it is aimed to reveal the definitions and importance of the concepts of food literacy, mindful eating and the relationship between these concepts with nutrition in order to provide the ideal health situation with an adequate and balanced diet in this increasing food variety and fast pace of life.
\end{abstract}

Keywords: Food literacy, Nutrition, Health, Mindful eating.

\footnotetext{
${ }^{1}$ Arş. Gör., Hakan BOR, Beslenme ve Diyetetik, Gümüşhane Üniversitesi Sağlık Bilimleri Fakültesi Beslenme ve Diyetetik Bölümü, hakanbor2009@hotmail.com, ORCID: 0000-0001-5430-4753

${ }^{2}$ Prof. Dr., Mendane SAKA, Beslenme ve Diyetetik, Başkent Üniversitesi Sağlık Bilimleri Fakültesi Beslenme ve Diyetetik Bölümü, saka@ baskent.edu.tr, ORCID: 0000-0002-5516-426X 


\section{GíRiş}

Genel olarak besin okuryazarlığ "ihtiyaçları karşılamak ve besin alımını belirlemek üzere yiyecekleri planlamak, yönetmek, seçmek, hazırlamak ve yemek için gerekli olan birbiriyle bağlantılı bilgi, beceri ve davranışların bir koleksiyonu" şeklinde tanımlanmıştır. Ayrıca besin okuryazarlığ 1 bireylerin, hane halklarının, toplulukların veya ulusların zamanla meydana gelen değişim sürecinde diyet kalitelerini korumalarını sağlayan ve diyet esnekliklerini destekleyen temel yapı taşıdır. Diğer yandan besin okuryazarlığının alt bileşenleri mevcuttur ve bunlar; "planlamak-yönetmek, seçmek, hazırlamak ve yeme" bileşenleri olmak üzere dört kategoride rapor edilmiştir. ${ }^{1}$

Yeme farkındalığı bireyin yemek yemeyle ilgili fiziksel ve duygusal hislerinin önyargısız olarak farkında olma durumu olarak tanımlanmaktadır. Ayrıca yeme farkındalığının daha sağlıklı vücut ağırlığında olmayı ve daha sağlıklı yeme alışkanlıklarına sahip olmayı teşvik ettiği bildirilmiştir. Bunun yanında yeme farkındalığı yeteneği, daha az dürtüsel yemek yemeyle azaltılmış enerji tüketimi ve daha sağlıklı atıştırmalık seçimleri ile ilişkilendirilmiştir. Bu ilişkilerden dolayı da yeme farkındalığının sağlıklı yemek yeme üzerinde büyük bir etkisi olduğu rapor edilmiştir. $^{2}$ Ayrıca yeme farkındalığının ağırlık yönetiminde etkili olduğu ve şekerleme tüketimini azalttığı farklı çalışmalarda ortaya konmuştur. ${ }^{3,4}$

$\begin{array}{ccc}\text { Beslenme } & \text { okuryazarlığı ve } \begin{array}{r}\text { yeme } \\ \text { farkındalığının } \\ \text { eksikliğinden }\end{array} \text { kaynaklı }\end{array}$ sağlıksız beslenmenin sebep olduğu obezite ve aşırı kilo önemli toplumsal problemlerdir. ${ }^{2}$ Yetişkinlerde aşırı kilolu olma beden kütle indeksi (BKI) değerlerinin $25 \mathrm{~kg} / \mathrm{m}^{2}$,ye eşit veya üzerinde olması durumunda, obezite ise BKİ değerlerinin $30 \mathrm{~kg} / \mathrm{m}^{2}$ ye eşit veya üzerinde olması durumunda teşhis edilmektedir.5 Ayrica genel ve abdominal obezite ile düşük posa tüketimi gibi sağlıksız yaşam tarzı davranışlarının ilişkili olduğu

rapor edilmiştir. ${ }^{6}$ Yapılan bazı çalışmalar abur cubur ve hazır yemek (fast food) tüketiminin obeziteyle ilişkili olduğunu tespit etmiştir., ${ }^{7,8}$
Diğer yandan obezite ve aşırı kilo dislipidemi, tip 2 diyabet, koroner kalp hastalığ kesesi rahatsızlığı, kireçlenme, uyku apnesi, solunum problemleri, çeşitli kanser türleri dahil olmak üzere birçok rahatsızlığın oluşmasına yol açmakla beraber bunlardan kaynaklı morbidite ve mortalite riskini önemli ölçüde artırmaktadır. ${ }^{5}$

\section{Besin Okuryazarlığı}

Günümüzde besin okuryazarlığı teriminin ortaya çıkmasıyla beraber literatürde besin okuryazarlığına dair çok çeşitli tanımlar ortaya konmuştur. $\mathrm{Bu}$ tanımların bazıları şunlardır: Öncelikle 2013 yılında Desjardins ve arkadaşları tarafından besin okuryazarlığı insanların kendileri ve aileleri için günlük, sağlıklı, lezzetli, uygun fiyatlı yemek hazırlığını sürdürmelerine yardımcı olan bir dizi beceri ve nitelik olarak tanımlanmaktadır. ${ }^{9}$ Bunun yanında 2017 yılında Truman ve arkadaşları yaptıkları çalışmada besin okuryazarlığını iki farklı şekilde tanımlamıştır. ${ }^{10}$ İlk olarak besin okuryazarlığı, yiyecek kökenleri ve sistemleri, bireysel ve kolektif yiyecek deneyimleri, yiyecek tanımlaması, yiyeceğin fiziksel, duygusal ve zihinsel etkileri ile yiyeceğe ilişkin temel yetenekler hakkında geniş bilgi ve beceri kümelerini içeren bir tanım olarak ifade edilmiştir. İkinci tanımda ise besin okuryazarlığ 1 , insanların yiyeceklerle ilgili eylemlerde bulunmalarını ve daha geniş bir besin sistemiyle ilişkilerini eleştirel olarak düşünmelerini sağlayan bir bilgi, anlayış ve farkındalık temeli olarak tanımlanmaktadır. Son olarak 2018 yılında Slater ve arkadaşları tarafindan besin okuryazarlığı çerçevesi işlevsel (besine duyulan güven ve güçlendirme), ilişkisel (yemek yoluyla neşe ve anlam) ve sistemsel (besin sistemleri için eşitlik ve sürdürülebilirlik) üç yeterlilik faktörüyle tanımlanmıştır. ${ }^{11}$

\section{Besin Okuryazarlığının Bileşenleri}

Besin okuryazarlığının ihtiyaçları karşılamak ve alımı belirlemek adına yiyecekleri "planlamak-yönetmek, seçmek, hazırlamak ve yemek" için gerekli olan 
birbiriyle ilişkili bilgi, beceri ve davranışlardan oluşan dört bileşeni mevcuttur. ${ }^{1}$

\section{Planlama ve Yönetme Bileşeni}

Besin okuryazarlığının planlama ve yönetme bileşeni "yiyecek ve yemek için zaman ayırmak, bu zamanın ayrılmasına olanak sağlayacak bir plana sahip olmak ve beklenen bir sonucu ortaya çıkarabilecek uygun bir plan inşa etme becerisine sahip olmak" olarak tanımlanmaktadır. Planlama ve yönetme bileşeninin 3 boyutu; "yemek için para ve zamanı öncelik olarak belirlemek, yiyecek alımını planlamak böylece yiyeceklere düzenli olarak erişebilmek, şartlar veya ortamdaki değişikliklerden bağımsız olarak ve uygulanabilir besin kararları almak" faktörlerini içerir. ${ }^{1}$

\section{Seçme Bileşeni}

Vidgen ve Gallegos ${ }^{1}$ seçme bileşenini "bakkaliye eşyalarının seçimi... ve yiyecek servisi eşyaları" olarak tanımlamaktadır. Seçme bileşeninin 3 alt faktörü ise "birden fazla kaynaktan besinlere erişme, avantaj, dezavantajları bilme ve bir besin ürününde ne olduğunu belirleme ve besin kalitesini değerlendirme" şeklinde belirlenmiştir. ${ }^{1}$ Özellikle besin fiyatlarının, fazla kilolu ve obez kadınlar için daha zayıf olan akranlarına kıyasla daha önemli olduğu tespit edilmiştir. ${ }^{12}$

\section{Hazırlama Bileşeni}

Vidgen ve Gallegos ${ }^{1}$, hazırlık bileşenini temel düzeyde "yiyecekleri hazırlama yeteneği" olarak tanımlar. Hazırlık bileşeninin 2 faktörü "mevcut olan yiyeceklerden tadi iyi bir yemek yapmak ve besin hijyeninin, kullanımının temel prensiplerini uygulamak" tır. Kadınlarda pişirme becerilerinin tanımlanmış belirteçleri arasında eğitime katılım, bir evdeki yetişkin ve çocuk sayısı ile yemek pişirmeden alınan keyif düzeyi yer almaktadır. ${ }^{13}$ Kadınlar ayrıca zamanın yemek pişirme ve yemek hazırlama ile ilgili önemli bir faktör olduğunu belirtmişlerdir. Yemek pişirmeye zaman ayırmaya istekli olmak ve genel olarak yemek pişirmekten zevk almak yemek pişirme becerilerinin belirteçleri olarak gösterilmiştir.
Bununla birlikte hissedilen zaman bask1s1, pişirme öz yeterliliği ile ters orantılıdır; bu da kadınları kolay hazırlanabilir türden yiyecekler seçmeye yönlendirebilmektedir. ${ }^{14}$ Sağlık bilinci ve sağlıklı bir yemeğin hazırlanması pişirme becerilerinin, pişirme öz yeterliliğinin ve hazır yiyeceklere olan eğilimin azalmasının bir göstergesi olarak tanımlanmıştır. ${ }^{13,14}$

\section{Yeme Bileşeni}

Yeme bileşeni "yeme davranışı ve yeme davranışının sonuçları" olarak tanımlanmaktadır. Yeme bileșeninin temel 3 faktörü "yemeğin kişisel sağlık üzerinde bir etkisi olduğunu anlama, kişisel ihtiyaca göre besin alımını dengeleyebilme öz farkındalığı ve sosyal bir şekilde bir araya gelip yemek yiyebilme"dir. ${ }^{1}$ Yapılan bir çalışmada dar gelirli popülasyonlardaki randomize kontrollü yaşam tarzı müdahalelerinin sistematik bir incelemesi yapılmıştır. Dahil edilen 35 çalışmanın 13'ü diyetsel bir müdahaleyi konu almaktadır ve kadınlar tüm katılımcıların \%72,4'ünü teşkil etmektedir. Müdahale format1, kendi kendine yardım materyallerinden, bireysel ve grupla psikolojik danışma ve sınıflara kadar geniş bir yelpazede değişmektedir. Çalışma sonucu olarak bu diyet müdahalelerinin diyet kalitesi üzerinde küçük ama olumlu bir etkiye sahip olduğu rapor edilmiştir. $\mathrm{Bu}$ etkilerin bazılarının müdahale sonrasında 12 aya kadar veya daha uzun vadede muhafaza edilebildiği tespit edilmiştir. ${ }^{15}$

\section{Besin Okuryazarlığı ve Beslenme}

Truman ve arkadaşlarının kapsamlı incelemesinde besin okuryazarlığ tanımlarının çoğunda besin/sağlık seçenekleri ögesi görülmektedir ve bu durum eğitimin, sağl1k endişesiyle besin seçimine ve beslenme şekline etki edebileceği şeklinde anlamlandırılmaktadır. ${ }^{10}$ Ayrica Block ve arkadaşları $^{16}$ sağlıklı olmak için ihtiyaç duyulan besinlerin bileşenlerini; besin sosyalleşmesi, besin bulunabilirliği, besin pazarlamas1, besin politikası ve besin okuryazarlığı olmak üzere beş kategoriye göre sınıflamıştır ve bu sınıfların doğrudan ya da dolaylı olarak bireylerin besin seçimlerine 
etki ettiğini rapor etmiştir. Bunun yanında 2009 yılında Booth ve arkadaşları besin seçimlerine etki eden unsurları derlemişlerdir ${ }^{17}$. Kişilerin beslenme örüntüsüne ve beslenme alışkanlıklarına etki eden bu unsurlardan bazıları; bireyin muhitindeki hazır yemek restoranlarının sayıs1, ebeveynlerin satın aldığ atıştırmalıkların türleri, okul kafetaryasında satılan atıştırmalıkların türleri ve besin bulunabilirliği faktörleridir. ${ }^{17}$ Ball ve arkadaşları $^{18}$ tarafından yapılan bir başka çalışmada sağlıklı yiyecek mağazalarının coğrafi erişebilirliğinin önem ve etkilerine dikkat çekilmiş ve bu tür mağazaların Avustralya'nın daha çok ayrıcalıklı muhitlerinde yer aldı ğı rapor edilmiştir. Aynı zamanda çalışmada, hamur işleri ve fast food ürünleri gibi enerjisi çok yoğun olmayan ve bu nedenle fazla parayı hak etmediği düşünülen meyve ve sebzelerin tüketiminde sosyo ekonomik kısıtlamaların en çok rapor edilen engellerden biri olduğu ifade edilmiştir. $^{18}$ Giskes ve arkadaşları da sosyoekonomik kapasitenin, düşük sosyoekonomik seviyedeki bireylerin ne tür yiyecekleri satın alıp evlerine getirip tüketecekleri konusundaki eğilimi belirlediğini vurgulamıştır. ${ }^{19}$

\section{Besin Okuryazarlığı ve Sağlık}

Beslenme ve sağlık bilimi alanında sağlık ve besin okuryazarlığı arasında bir ilişkinin mevcut olduğu ve çevresel, kültürel, politik ve ekonomik faktörlere bağlı olarak bireylerin besin ile kişisel bir ilişkisi olduğu düşünülmektedir. $\mathrm{Bu}$ nedenle kötü besin seçimleri bireylerin sağlık durumlarının kötüleşmesine yol açmaktadır. ${ }^{20}$ Ayrıca Kanada Sosyal İşler, Bilim ve Teknoloji Senato Komitesi tarafindan 2016 yılında yayımlanan bir çalışmada da bu durum rapor edilmiştir. Komite aşırı vücut ağırlığı ile bağlantılı olarak yeme alışkanlıkları ve sağlık sorunları arasında bir ilişki olduğunu rapor etmiştir. ${ }^{21} \mathrm{Bu}$ konuda başka bir çalışmada ise Velardo besin okuryazarlığının tartışılmaz bir şekilde sağlık okuryazarlığ 1 becerilerine odaklandığını ve bir besin ortamındaki bilgi ve kapasiteleri araştırdığını savunmaktadır. ${ }^{22}$

\section{Yeme Farkındalı̆̆}

"Farkındalık" terimi bir dizi farklı uygulamaya atıfta bulunmak için kullanılabilmekle beraber farkındalık biraz farklı şekillerde kavramsallaştırılmıştır. ${ }^{23}$ Yeme farkındalığı, daha önceleri farkındalığın belli bir alt kümesiyken ondan ayırt edilebilir özelliklere sahip olduğu görülmüştür. ${ }^{24}$ Kabat-Zinn farkındalığ 1 , "şu anki anda, hatta ani olarak deneyim anının ortaya çıktığı anda, yargılayıcı olmayan bir biçimde, dikkat ederek ortaya çıkan farkındalık" olarak tanımlamaktadır. $\mathrm{Bu}$ tanım, şu andaki deneyime dikkat etmek ve ayrıca bu deneyime ilişkin yargılayıcı olmayan bir tavır almak olmak üzere iki ana fikri kapsamaktadır. ${ }^{25}$ Bishop ve Shapiro tarafından yapılan farkındalığın tanımında ise şu andaki deneyime dikkat etmenin dikkat düzenlemesi gerektirdiği vurgulanmaktadır. ${ }^{26}$

\section{Yeme Farkındalığı ve Beslenme}

Yeme farkındalığı bireye çok sayıda fayda sağlamaktadır. ${ }^{27}$ Bunlardan birisi beslenme davranışlarına olan pozitif etkisidir. ${ }^{2}, 28,29$ Yeme farkındalığının daha az enerji alımıyla ilişkili olduğu bulunmuştur. ${ }^{28}$ Bunun yanında yeme farkındalığına sahip bireylerin şekerli içecek, cips ve çubuk kraker tüketimlerinin daha düşük olduğu rapor edilmiştir. ${ }^{30}$ Ayrıca yeme farkındalığının enerji yoğunluğu yüksek besin alımını azalttığını tespit etmiştir. ${ }^{29}$ Gilbert ve Waltz yaptıkları çalışmada yeme farkındalığının meyve ve sebze tüketimini artırdığını ifade ederken, bir başka çalışma ise yeme farkındalığının artmasıyla beraber tıkınırcasına yeme davranışında azalma olduğunu rapor etmiştir. ${ }^{31,32}$ Levin ve arkadaşları ise yeme farkındalığının, tıkınırcasına yeme ve duygusal yeme bozukluğunda ortaya çıan ve obeziteye yol açan yeme davranışlarıyla negatif ilişkili olduğunu tespit etmiştir. ${ }^{33}$ Diğer yandan yeme farkındalığının porsiyon kontrolü üzerinde olumlu etkileri olduğu gösterilmiştir. ${ }^{29}$ Birçok geniş ölçekli meta analiz çalışmalarında da farkındalığın ağırlık denetimini ve sağlıklı beslenmeyi pozitif yönde etkilediği kabul edilmiştir. ${ }^{34-36}$ 


\section{Yeme Farkındalığı ve Sağlık}

Yeme farkındalığ 1 temelli müdahalelerin şişmanlık, kilo kaybı ve psikolojik rahatsızlıkların azaltılması gibi obezite ile ilgili davranışların azaltılmasında etkili bulunmuştur. $^{24}$ Prowse ve arkadaşları farkındalık ve yeme patolojisi konusunda yaptıkları bir çalışma sonucunda, farkındalık becerisinin artan yeme patolojisi düzeyleri ile ilişkili olduğunu göstermiştir. ${ }^{37}$ Bununla birlikte, sonuçlar, tarafsız kabul etme ve bilinçli cevap verme gibi farkındalık becerilerinin ise düşük yeme patolojisi düzeyleri ile ilişkili olduğunu göstermiştir. ${ }^{37}$ $\mathrm{Bu}$ sonuçlar, artan psikopatoloji seviyelerinin, gözlem becerileri dışında azalmış farkındalık becerileri düzeyleri ile ilişkili olduğu önceki araştırma bulgularıyla tutarlıdır. ${ }^{38}$

Ayrıca, farkındalıkla cevap verme ve tarafsız kabullenme ile ilgili becerilerin yeme patolojisine karşı artan esneklikle ilgili olabileceğine dair kanıtlar vardır. Khan ve Zadeh tarafından yapılan bir başka araştırma, yeme farkındalığının genel psikolojik iyi oluş ile pozitif ilişkili olduğunu göstermiştir. ${ }^{39}$ Ayrıca farkındalık, yeme bozukluğunun bileşenleri olan depresyonu ve anksiyeteyi azaltma gibi olumlu sağlık sonuçları ile de ilişkili bulunmuştur. Bunun yanında anoreksiya nervozalı bireyler kilo alma korkusuyla meşgul olduklarından kilo almalarını önlemeye yardımc olacak davranışlar sergilemektedirler. Bulimiya nervozalı bireyler ise yemeklerini kontrol edemez ve tehlikeli telafi edici davranışlarda bulunurlar. Tikınırcasına yeme bozukluğu olan bireylerde de yemek yeme üzerinde kontrol kaybı mevcuttur ve bu bireyler açlık ya da tokluk işaretlerinin farkında değildirler. ${ }^{40}$

\section{SONUÇ VE ÖNERILER}

Sonuç olarak besin okuryazarlığı, bireylerin günümüz karmaşı besin sisteminde sağl1klı ve sağl1ksız besin maddelerini birbirlerinden ayırt edebilmesini ve bunların tüketim miktarını malnütrisyon veya obeziteye sebebiyet vermeyecek şekilde ihtiyaçlarına göre belirleyebilmelerini sağlamaktadır. Sonrasında ise sağlıklı besin hazırlama yöntemleriyle hazırlayabilmelerini ve sağlıklı yemek yeme davranışlarına uygun olarak tüketebilmelerini sağlayarak bireyleri malnütrisyon, obezite ve bunlardan kaynaklı kronik hastalıklardan korumaktadır. Sağlıklı beslenme bilgisiyle de bireylerin sağlık ve iyilik halinin sürdürülmesine yardımcı olmaktadır.
Yeme farkındalığ ise bireylerin önyargısız bir biçimde yediklerinin bilincinde olmasına ve yemek yeme konusunda kontrolü ellerinde tutmalarına yardımc olmaktadır. Ayrica bireylerin yeme bozukluklarına yakalanmalarının ve yeme bozukluklarının sebep olabileceği obezite ve diğer rahatsızlıkların önüne geçebilmektedir. $\mathrm{Bu}$ bilgiler 1şığında günümüz toplumunda bireylerin sağlıklı bir yaşamın temeli olan sağlıklı beslenme eylemini doğru bir şekilde uygulaması için yeterli düzeyde besin okuryazar olmaları ve yeme farkındalığına sahip olmaları büyük bir önem arz etmektedir.

KAYNAKLAR

1. Vidgen, H.A. and Gallegos, D. (2014). "Defining Food Literacy And Its Components". Appetite, 76, 50-59. https://doi.org/10.1016/j.appet.2014.01.010

2. Jordan, C.H, Wang, W, Donatoni, L. and Meier, BP. (2014). "Mindful eating: Trait and state mindfulness predict healthier eating behavior". Personality and Individual Differences, 68, 107-111.

3. Timmerman, G.M. and Brown, A. (2012). "The effect of a mindful restaurant eating intervention on weight management in women". J Nutr Educ Behav, 44 (1), 22-28. https://doi.org/10.1016/j.jneb.2011.03.143

4. Mason, A.E, Epel, E.S, Kristeller, J, Moran, P.J, Dallman, M, Lustig, R.H, Acree, M, Bacchetti, P, Laraia, B.A, Hecht, F.M. and Daubenmier, J. (2016). "Effects of a Mindfulness-Based Intervention on Mindful Eating, Sweets Consumption, and Fasting Glucose Levels in Obese Adults: Data From The SHINE Randomized Controlled Trial". J Behav Med, 39 (2), 201-213. https://doi.org/10.1007/s10865-015-9692-8 
5. National Institutes of Health. (1998). "Clinical Guidelines on The Identification, Evaluation, and Treatment of Overweight And Obesity In Adults". Noe Initiative, 6 (2), 51-209.

6. Cureau, F, Sparrenberger, K, Bloch, K, Ekelund, U. and Schaan, B. (2018). "Associations of Multiple Unhealthy Lifestyle Behaviors With Overweight/Obesity and Abdominal Obesity among Brazilian Adolescents: A Country-Wide Survey". Nutrition, Metabolism and Cardiovascular Diseases, 28 (7), 765-774.

7. Mansouri-Tehrani, MM, Hashemi-rad, S, Hajiha, T, Mousavian, S. and Rezazadeh, A. (2019). "Association of Junk Food Consumption With Overweight-Obesity Among Preclinical Medical Students of Shahid Beheshti University of Medical Sciences". Social Determinants of Health, 5 (1), $2-10$.

8. Banik, R, Naher, S, Pervez, S. and Hossain, M. (2019). "Fast Food Consumption and Obesity among Urban College Going Adolescents: A Cross-sectional Study". Obesity Medicine, 10 (1), 161 .

9. Desjardins, E. (2013). Making Something Out of Nothing: Food Literacy Among Youth, Young Pregnant Women and Young Parents who are at Risk for Poor Health. London. Ontario Public Health Association Publishing.

10. Truman, E, Lane, D. and Elliott, C. (2017). "Defining Food Literacy: A Scoping Review". Appetite, 116, 365-371. https://doi.org/10.1016/j.appet.2017.05.007

11. Slater, J, Falkenberg, T, Rutherford, J. and Colatruglio, S. (2018). "Food Literacy Competencies: A Conceptual Framework For Youth Transitioning To Adulthood". International Journal of Consumer Studies, 42 (5), 547-556.

12. Dressler, H. and Smith, C. (2013). "Food Choice, Eating Behavior, And Food Liking Differs Between Lean/Normal and Overweight/Obese, Low-Income Women". Appetite, 65, 145-152.

13. Hartmann, C, Dohle, S. and Siegrist, M. (2013). "Importance of Cooking Skills For Balanced Food Choices". Appetite, 65, 125-131. https://doi.org/10.1016/j.appet.2013.01.016

14. Beshara, M, Hutchinson, A and Wilson, C. (2010). "Preparing Meals Under Time Stress. The Experience of Working Mothers". Appetite, 55 (3), 695-700. https://doi.org/10.1016/j.appet.2010.10.003

15. Bull, E.R, Dombrowski, S.U, McCleary, N. and Johnston, M. (2014). "Are Interventions For Low-Income Groups Effective in Changing Healthy Eating, Physical Activity and Smoking Behaviours? A Systematic Review and MetaAnalysis". BMJ Open, 4 (11), 46-60. https://doi.org/10.1136/bmjopen-2014-006046

16. Block, LG, Grier, SA, Childers, TL, Davis, B, Ebert, JE, Kumanyika, S, Laczniak, RN, Machin, JE, Motley, CM. and Peracchio, L. (2011). "From Nutrients To Nurturance: A Conceptual Introduction To Food Well-Being". Journal of Public Policy \& Marketing, 30 (1), 5-13.

17. Booth, S.L, Sallis, J.F, Ritenbaugh, C, Hill, J.O, Birch, L.L, Frank, L.D, Glanz, K, Himmelgreen, D.A, Mudd, M, Popkin, B.M, Rickard, K.A, St Jeor, S. and Hays, N.P. (2001). "Environmental and Societal Factors Affect Food Choice And Physical Activity: Rationale, Influences, and Leverage Points". Nutr Rev, $59 \quad$ (2), 21-39. https://doi.org/10.1111/j.1753-4887.2001.tb06983.x

18. Ball, K, Timperio, A. and Crawford, D. (2009). "Neighbourhood Socioeconomic Inequalities in Food Access and Affordability". Health Place, 15 (2), 578-585. https://doi.org/10.1016/j.healthplace.2008.09.010

19. Giskes, K, Turrell, G, Van Lenthe, F.J, Brug, J. and Mackenbach, J.P. (2006). "A Multilevel Study of SocioEconomic Inequalities in Food Choice Behaviour and Dietary
Intake among The Dutch Population: The GLOBE Study". Public Health Nutrition, 9 (1), 75-83

20. Sumner, J. (2013). "Food Literacy and Adult Education: Learning To Read The World By Eating". Canadian Journal for the Study of Adult Education, 25 (2), 79-92.

21. Canada Parliament Senate Standing Committee on Socia Affairs. (2016). "Obesity in Canada: A Whole of Society Approach for A Healthier Canada". Erişim adresi: https://sencanada.ca/content/sen/committee/421/soci/rms/01 mar16/NewsRelease-e.htm (Erişim tarihi: 11.02.2021).

22. Velardo, S. (2015). "The Nuances of Health Literacy, Nutrition Literacy, and Food Literacy". J Nutr Educ Behav, 47 (4), 385-389. https://doi.org/10.1016/j.jneb.2015.04.328

23. Tapper, K. (2017). "Can Mindfulness Influence Weight Management Related Eating Behaviors? If So, How?". Clinical psychology review, 53, 122-134.

24. Clementi, C, Casu, G. and Gremigni, P. (2017). "An Abbreviated Version of the Mindful Eating Questionnaire". J Nutr Educ Behav, 49 (4), 352-356. https://doi.org/10.1016/j.jneb.2017.01.016

25. Kabat-Zinn, J. (2003). "Mindfulness-based Interventions in Context: Past, Present, and Future". Clinical psychology: Science and practice, 10 (2), 144-156.

26. Bishop, S.R, Lau, M, Shapiro, S, Carlson, L, Anderson, N.D, Carmody, J, Segal, Z.V, Abbey, S, Speca, M. and Velting, D. (2004). "Mindfulness: A Proposed Operational Definition". Clinical psychology: Science and practice, 11 (3), 230-241.

27. Davis, D.M. and Hayes, J.A. (2011). "What Are The Benefits of Mindfulness? A Practice Review of PsychotherapyRelated Research". Psychotherapy, 48 (2), 198.

28. Arch, J.J, Brown, K.W, Goodman, R.J, Della Porta, M.D, Kiken, L.G. and Tillman, S. (2016). "Enjoying Food Without Caloric Cost: The Impact of Brief Mindfulness on Laboratory Eating Outcomes". Behaviour Research and Therapy, 79, 2334.

29. Beshara, M, Hutchinson, A.D. and Wilson, C. (2013). "Does Mindfulness Matter? Everyday Mindfulness, Mindful Eating and Self-Reported Serving Size of Energy Dense Foods among A Sample of South Australian Adults". Appetite, 67, 25-29.

30. Anderson, A, Caine-Bish, N, Gordon, K. and Falcone, T. (2015). "Effects of an Acute Mindful Eating Exercise on Food Selection Type and Quantity in College Students". Journal of Nutrition Education and Behavior, 47 (4), 88.

31. Gilbert, D. and Waltz, J. (2010). "Mindfulness and Health Behaviors". Mindfulness, 1 (4), 227-234.

32. Roberts, KC. and Danoff-Burg, S. (2010). "Mindfulness and Health Behaviors: Is Paying Attention Good For You?". Journal of American college health, 59 (3), 165-173.

33. Levin, M.E, Dalrymple, K, Himes, S. and Zimmerman, M. (2014). "Which facets of Mindfulness Are Related To Problematic Eating among Patients Seeking Bariatric Surgery?". Eating behaviors, 15 (2), 298-305

34. Carrière, K, Khoury, B, Günak, M. and Knäuper, B. (2018) "Mindfulness-based Interventions For Weight Loss: A Systematic Review and Meta-Analysis". Obesity Reviews, 19 (2), 164-177.

35. O'Reilly, G.A, Cook, L, Spruijt-Metz, D. and Black, D.S (2014). "Mindfulness-based interventions for obesity-related eating behaviours: a literature review". Obes Rev, 15 (6), 453-461. https://doi.org/10.1111/obr.12156

36. Ruffault, A, Czernichow, S, Hagger, M.S, Ferrand, M Erichot, N, Carette, C, Boujut, E. and Flahault, C. (2017) "The Effects of Mindfulness Training on Weight-Loss and Health Related Behaviours in Adults with Overweight and 
Obesity: A Systematic Review and Meta-analysis". Obes Res Clin Pract, $11 \quad$ (1), 90-111. https://doi.org/10.1016/j.orcp.2016.09.002

37. Prowse, E, Bore, M. and Dyer, S. (2013). "Eating Disorder Symptomatology, Body Image, and Mindfulness: Findings in A Non-Clinical Sample". Clinical Psychologist, 17 (2), 77 87.

38. Baer, R.A, Smith, G.T, Hopkins, J, Krietemeyer, J. and Toney, L. (2006). "Using Self-Report Assessment Methods
To Explore Facets of Mindfulness". Assessment, 13 (1), 27 45.

39. Khan, Z. and Zadeh, Z.F. (2014). "Mindful Eating and It's Relationship with Mental Well-Being". Procedia-Social and Behavioral Sciences, 159, 69-73.

40. American Psychiatric Association. (2013). Diagnostic and Statistical Manual of Mental Disorders (DSM-5®). America. American Psychiatric Association Publishing. 